\title{
A Translation Deviation Analysis of the English Version Snow in Midsummer - from the Systemic Functional Approach
}

\author{
Guangtao Cao ${ }^{1, *}$ Zilei Liu $^{2}$
}

${ }^{1}$ Forieign Languages Department, Guangdong University of Education, Guangzhou, Guangdong 510303, China

${ }^{2}$ School of Foreign Languages, Fujian Normal University, Fuzhou, Fujian 350007, China

*Corresponding author. Email: 1025420805@qq.com

\begin{abstract}
This paper attempts to study the English translation quality of Yuan Zaju from the perspective of ideational function, discourse function and interpersonal function, taking the translation Snow in Midsummer by Yang Xianyi and Gladys Yang as a case study. Yang's English translation fits the original background, the language is exquisite, the text is fluent, but there are still some inappropriate points. First of all, in terms of dictions, there are some omission and misinterpretation of the cultural allusions, or the atmosphere of cultural simplification, which not only reduces the literariness of the translation, but also leads to the ambiguity of conceptual differentiation. Secondly, in terms of syntax, some of the sentences in the translation fail to serve as a connecting link and highlight the cultural background. In general, there are some conceptual, textual and interpersonal errors in the English translation, which reduce the conformity between the quality of the translation and the original text.
\end{abstract}

Keywords: systemic functional linguistics, ideational function, discourse function, interpersonal

function, translation study, Snow in Midsummer

\section{INTRODUCTION}

Snow in Midsummer is a famous drama in Yuan dynasty, and considering its popularity, Snow in Midsummer was translated into different English versions. Yang Xianyi \& Gladys Yang's version enjoys influential popularity with its distinctive features like fluency, coherence, vividness and so on. This paper will analyze the translation deviation from Halliday's SFL(Systemic Functional Linguistics) approach.

Christopher S. Butle (2005) started his study from functional grammar, giving great attention on the role and reference grammar and systemic functional grammar.[1] Catherine L (2015) gave a report on initial steps in a potential pathway into developing critical language awareness in teachers and young children by introducing the notion of "author attitude" in science texts.[2] Williams (2017) probed into the concept of abstraction in SFL.[3]

*Fund: Shaoguan social science planning project in 2019 "A study on the translation of classical opera into English based on functional approaches - with a brief discussion on Liao Yan's plays and their translation" (Z2019007)
Huang Guowen (2004) illustrated the SFL in translation study generally, offering us a general and clear understanding of SFL.[4] Li Wanlin (2019), found that Yang Xianyi used the ethical modes and translation methods in their works, so she started to study the culture-loaded words in Snow in Midsummer.[5]

\section{SFL APPROACH FOR TRANSLATION} ASSESSMENT OF THE TRANSLATION OF SNOW IN MIDSUMMER

Bronislaw Malinowski used "context of situation" to explore semantics, arguing that discourse should be understood in all life situations, and that the discourse meaning was essentially the activity of the people. Furse recognized that language study should use both functional and sociological approaches. Furse believed that the analysis utterance meaning was the ultimate goal of linguistics; Given that utterance was carried out in a real context, the meaning derived from them should be related to the context. Halliday inherited two principles from Furse, "context of situation" and the definition of "system". The former believed that 
language has great closeness while the later received the impact of typical social situations. [6]

Snow in Midsummer is the master piece of Guan Hanqing. Four translation versions exist according to Cryril Birch. The Foreign Languages Press published Mr. Yang Xianyi and Ms. Glady Yang's translation in 1958. Chung-wen Shih's translation was published by Cambridge University Press in 1972. Among these versions, Yang Xianyi \& Gladys Yang's translation shares more popularity with its distinctive features like fluency, coherence and vividness.[7]

Yang's translation is very high in quality. But still it has some translation errors. From the traditional translation assessment approach, the translation deviation in this version can be classified into word level and sentence level without considering their functions.

\section{A. Translation deviation in word level}

A word is a combination of words and words, including words, phrases and the whole vocabulary. Seeing from a whole passage, not only the phases but also the passage can be influenced by words. Through research, several errors in dictation can be found within Snow in Midsummer:

- You / "秀才"

Since the Yuan and Ming dynasties, scholars are called "秀 $才 "$, which is the appellation of ancient China. The talk between mother Cai and Dou Tianzhang, highlights the strong cultural background of appellation language in ancient China. However, the translation simply translates the term "scholar" in English, which cannot reflect its colloquial culture.

- This fellow, keep / "成合"

"成合" causes unclear idea. When translating the appellations, there are strong emotional mood, which simplifies the meaning of the original text and weakens the interpersonal function.

- Confuses the wicked with the good / "盗跖颜 渊"

This famous allusions is from the ancient Chinese Spring and Autumn period, "盗跖" was a mountain governor, "颜渊" was Confucius's most virtuous student who almost reached the realm of saints, but died of illness. They separately represent evil and good and the evil one has a long life while another die young, this metaphor reveals that the fate of good and evil people is not fair. On the premise of knowing the meaning of allusions, the translation does not reveal the implied meaning, so that the resonance and situations in this paper is greatly weakened.
- Hair is white / "须发"

The term "须发" refers to the general term for beard and hair. The original text omitted the translation of beard, but only "发" is translated.

- Huai River, district / "扬州"

The ancient name of "扬州" is "广陵", "江都", "渭阳" "扬州" has a long history, located in the interchange between Yangtze River and Beijing-Hangzhou Grand Canal. "楚州", set up in Sui Dynasty of China, is now in Jiangsu Province. The translation simplifies the meaning of the two places and replaces with the concept words only, which not only obscure the accuracy of the location, but also cannot convey the conceptual meaning.

\section{B. Translation deviation in sentence level}

A sentence is the composition of words and phrases, which can express a complete meaning, such as telling someone something, asking for or stopping a question, expressing a feeling, indicating the continuation or omission of a passage. Through research, several errors in sentences can be found within Snow in Midsummer:

- Graves are dry, for new clothes / "坟头上土脉 犹湿，架儿上又换新衣。"

In the story of Ordinary Words to Warn the World in Ming Dynasty written by Feng Menglong, a man named Zhuang Sheng visited the mountain, saw many graves, he suddenly saw a new grave, the earth was wet. A young woman, sitting in this grave, waved her fan before the grave, Zhuang felt strange and asked her. The woman said that the grave was his poor husband, who unfortunately died. People said that she cannot marry others until the grave was dry, so she waved the fan to dry up the grave. The translation fail to convey the strong emotional meaning when use direct translation, weakening the figurative function of allusions.

- As discerning as a mirror / "明如镜，清似水"

In the original text, "明如镜，清似水" in the way of comparison, highlight its exquisite words, "镜" and "水" as metaphors, express the official flattery between common people and the officials. But the omission of the second half of the sentence "清似水", not only destroyed the beauty of the original comparison, but also weakened the subtle emotional tone conveyed in the play.

\section{- Be quiet / "打嘴"}

"打嘴" is the elder's criticism towards young people, is full of harsh and majestic emotional 
attitude. The translation is too flat and unmixed with a strong tone of attitude.

- ...Donkey tried... / "就将他爷儿两个领到家中， 过其日月。

The omission of the middle sentence results in the loss of the meaning.

\section{The translation deviation from ideational function}

The meaning here consist of three basic contents, semantic, pragmatic and textual. In general, a good translation is equivalent to the source text in meaning, and the ideational and interpersonal concept must be clearly revealed. [8]

As the material foundation of the information content in the text, Ideational meaning is the basis to the existence of the text. The main Ideational Deviation in the Snow in Midsummer are as follows.

- Taken the examinations / "诰命"

"诰命" refers to the imperial examination title or official title, the situation means that he has not obtained any official or merit title, so the author mistranslated the intended meaning.

\section{- Spring examinations / "春榜"}

"春榜" is also called "春膀", in Yuan Dynasty, "春 榜" also refers to the "进士" examination, so the literal translation of the original words fail to express it real meaning. Respecting the cultural background and following the habit of expression are the principles in translation.

- Money for the road / "盘缠"

"盘缠" refers to road expense. Ancient money is a hole in the middle of the metal coins, commonly uses ropes to string a thousand coins together and then hang up. When people go out to visit relatives, it is both easy to carry and safe, so the ancient people called this travel expenses "tangling". The translation simplifies the meaning and translation should be professional.

- At the end of the road / "巷口"

"巷口" refers to the entrance and exit of the lane. "巷口" is a narrow passage of small streets in China It is a colloquial culture with national, regional and vigorous vitality in China. The translation is not equal to the meaning of the original text, which makes the readers confuse and misunderstand the meaning of the original words.

- Sword / "刀"
This scene expresses the talk when Dou E is about to be decapitated. "斩首", the principle is to cut the neck, that is, to separate the head from the trunk. Looking at the diversity and cruelty of all kinds of capital punishment, "斩首" has always been regarded as an easy penalty, which will not cause physical mutilation of the sentenced person, but because the intercepted part is quite important and can lead to immediate death. Ancient Chinese cutting tools used for beheading are mostly thick beheading knives, while the original text "sword" refers to long and slender swords.

The ideational function in Snow in Midsummer can be highly reflected. Paying efforts on analyzing the translation deviation from ideational function can not only help to obey the cultural background of Yuan dynasty, but also advocate the famous plays in China.

\section{The translation deviation from discourse function}

Discourse analysis is closely connected with the specific relationship between discourse and context. Discourse refers to a linguistic unit above the sentence level. People will not put unrelated words or phrases randomly, but interact with certain purpose. In communication, they are able to reveal a coherent, holistic meaning, which shows an important feature of a text: coherence. [9] The main discourse deviation in the translation are as follows.

\section{- Here / "荆州"}

"荆州", the ancient name of "江陵", a prefecturelevel city of Hubei Province. "荆州" is replaced by the adverb of place, which blurs the important place that the play wanted to express.

\section{- Very well / "他又勒杀我。"}

This dialogue took place when mother Cai was forced by Fu Jing and his father. The emotional words added is not precise enough to reveal the feeling of the character, easily to cause readers' confusion.

- Worked in different cities and counties / "撞 府冲州"

"撞府冲州" means become a vagrant and work along the wharf, which also describes rich experience. In addition, "䦶阐" means struggling and show that money is hard to gain. The translation reduces the level in which the author wants to stress.

Discourse function matters a lot. The application of discourse function can help us find out some errors in Snow in Midsummer from incoherence, omission and so on. Only when we 
obey the principle of discourse function, can a translation text really be welcomed by readers.

\section{E. The translation deviation from interpersonal function}

Interpersonal function refers to the communication and relationships among people, thus to exert influence to people's behavior or to express their feeling. In language function, text type and its translation method, drama literature has three functions of information, expression and infection, while the play Snow in Midsummer, as a historical eulogy, its expression and infection function are particularly prominent and has distinctive interpersonal significance. So interpersonal function should be included in the most significant criteria for translation quality assessment.[10] The main Interpersonal deviation in the translation are as follows.

- Name / "小名"

"小名" refers to the name used in childhood. It's usually a baby name, some places called it a nickname. China's Qin and Han dynasties have the saying "小名", which are used only between family. The translation confuses the distinction between formal name and nick name, which greatly weakens interpersonal meaning.

- I / "小子"

"小子" in ancient China refers to the selfproclaimed title, means common people, boy, son, or immoral man. In this article, "小子" contains a strong emotional feeling, refers to immoral man. The translation of Chinese ancient self-proclaimed appellations, use cultural simplification, the interpersonal function of the original text is misinterpreted.

- I / "小人"

"小人 " refers to the person with a mean personality or common people. In the translation of Chinese ancient self-proclaimed predicates, cultural simplification is used and the interpersonal function of the original text is mistakenly translated.

\section{- You / "厮"}

"厮" in ancient China has two main meanings : (1) the ancient male slaves or petty servitude (2) ancient address to people. When translated the predicate with strong emotion, the original meaning is simplified, but replaced by the English name, it weakens the interpersonal function of the original text.

- She, her / "婆娘"
"婆娘" refers to women, especially domestic maid. The predicate is with strong emotion, the original meaning is simplified, weakening the interpersonal function.

- Girl / "贱人"

"贱人" generally refers to the humble, low moral status of people, is the old abusive words against women. Dou Tianzhang, the protagonist of the original text, as an upright official, has a strong emotion in the criticism and disgust of his daughter Dou E before he known the truth. However, the translation simplifies the title, and fails to express the affection of the story.

Interpersonal function reveals the interaction and attitude of the speaker and the receiver in the context. Snow in Midsummer has a unique interpersonal significance. Thus, interpersonal function should be one of the most significant standard to evaluate translation quality.

\section{CONCLUSION}

With SFL, especially its ideational function, interpersonal function and discourse function, many translation mistakes can be revealed. Functional linguistics has more specific and scientific normative translation research paths and evaluation categories. Translation studies of systemic functional method focused on parametric models of formal correspondence, text equivalence, discourse and communicative functions. The three theoretical functions are ideational function, interpersonal function and discourse function, which have constructed a new evaluation model of threedimensional translation evaluation. Yang Xianyi and Gladys Yang's translation has outstanding achievements, but even the translation from the master is flawed. Among these translation errors, there are much omission and misinterpretation of the cultural allusions which not only reduces the literariness of the translation, but also leads to the ambiguity of conceptual differentiation. Some of the translation fail to serve as a connecting link and highlight the cultural background. These deviation can be classified into conceptual, textual and interpersonal errors, which reduces the conformity between the quality of the translation and the original text.

\section{References}

[1] Christopher S. Butler. Focusing on focus: A comparison of Functional Grammar, Role and Reference Grammar and Systemic Functional Grammar [J]. Language Sciences, 2005,27(6)

[2] Catherine L. O' Hallaron, Annemarie S. Palincsar, Mary J. Schleppegrell. Reading science: Using systemic functional 
linguistics to support critical language awareness [J]. Linguistics and Education,2015,32.

[3] Jamie Williams, Noah Russell,Derek Irwin. On the notion of abstraction in systemic functional linguistics [J]. Functional Linguistics,2017,4(1).

[4] Huang Guowen.A functional linguistic approach to translation studies [J]. China translation,2004(05):17-21.

[5] Li Wanlin.A study on the English translation of Dou e Yuan and Chinese culture-specific words in the perspective of Chesterman s translation ethics-A Case Study of Yang Xianyi's Translation [J]. Overseas English,2019(17):139141

[6] Zhang Del.The development of systemic functional linguistics in China $[\mathrm{J}]$. Chinese Foreign Languages, 2006(02):27-32.

[7] Chen Na.A Comparative Study of the Translation Strategies of Allusions in The Injustice to Dou E [D]. Dalian Maritime University,2011.

[8] Yan Xiaopin.The influence of register in systemicfunctional Linguistics on translation $[\mathrm{J}]$. Journal of Cangzhou Teachers College,2005(03):41-42.

[9] Guan Xiaofa. A systemic-functional approach to grammatical metaphor [D]. Shanghai International Studies University, 2006.

[10] Hu Zhuanglin. On the present situation and development trend of systemic functional linguistics [J]. Foreign Language Education in China,2013,6(02):70-74+81. 